\title{
La mecánica de producción de los imaginarios urbanos: dos ejemplos de investigación para el caso de Santiago de Chile.
}

The mechanics of prodiction of "urban imaginaries": two examples for the case of SantiagoChile

Luis Campos Medina, Romina Álvarez Bové

\section{Filiación}

Universidad de Chile

E mail: luiscampos@uchilefau.cl, ralvarez@uchilefau.cl

Primera versión recibida en: 11 de enero, 2015

Última versión recibida en: 29 de diciembre, 2015

\section{Resumen}

La producción de investigaciones sobre imaginarios urbanos ha sido abundante en América Latina. Sin embargo, tales investigaciones generalmente carecen de una descripción del modo en que los imaginarios urbanos se producen $y$, en consecuencia, de una propuesta explícita respecto del modo en que tal proceso puede ser analizado.

En este artículo proponemos una perspectiva de análisis para abordar la producción de imaginarios urbanos. Para ello, hacemos una revisión bibliográfica de obras fundamentales en este campo de estudios y entregamos nuestra propuesta sobre lo que hemos llamado "mecánica" de producción de imaginarios. Para clarificar nuestro planteamiento hacemos referencia a dos casos de estudio, el concurso de micro-relatos "Santiago en 100 palabras" y la Revista "Vivienda y Decoración", del diario El Mercurio. A partir de ellos, concluimos destacando los aspectos generalizables de esta propuesta.

De acuerdo a nuestro planteamiento, la mecánica de producción de imaginarios se caracteriza por ciertas formas específicas de representar la ciudad que, producto de su difusión y reiteración sistemática, devienen marcos perceptivos de la ciudad, y se instalan como disposiciones para la acción, dando forma a nuestras experiencias y generando un marco interpretativo para nuevas representaciones que circulan en el medio urbano.

\section{Palabras Claves}

Imaginarios urbanos; trasfondo; publicidad inmobiliaria; micro-relatos; Santiago de Chile.

\begin{abstract}
Research on urban imaginaries has proliferated in Latin America for the past years. However, apparently no one has tackled the issue of how the image of the city comes to be. Therefore, there is a lack of explicit propositions regarding the way in which the process of production of urban imagery could be analyzed.

In this article we propose a framework for the analysis of the production of urban imaginaries, by reviewing the most relevant literature in the field, which allows us to develop what we called the "mechanics" of production of urban imaginaries. Subsequently, in order to clarify our proposal, we refer to two case studies: the "Santiago in 100 words" short-story competition and the "Vivienda $y$ Decoración" newspaper insert.

According to our analysis, the "mechanics" of production of urban imaginaries is characterized by specific ways of representation used to depict urban environments, that due to their massive distribution, become perceptual frameworks of the city, getting fixed as the foundations for general action, giving shaping our experiences and permeating our interpretations of new imaginaries that come into place.
\end{abstract}

\section{Keywords}


Urban imaginaries; real estate publicity; short-stories; Santiago-Chile.

\section{Sumario}

Introducción

1 La discusión sobre imaginarios sociales

2 La mecánica operatoria de los imaginarios urbanos

3 Ejemplo 1. El concurso "Santiago en 100 palabras": textos literarios en la producción de imaginarios urbanos

4 Ejemplo 2. La publicidad inmobiliaria en la construcción de imaginarios urbanos

5 Conclusión

Referencias

\section{Introducción}

En un texto del año 2002, Adrián Gorelik expresaba su malestar con la trayectoria que había seguido la perspectiva de los imaginarios urbanos, en tanto modo de aproximación a la comprensión de la ciudad. Señalaba el autor que nunca se habló tanto de imaginarios urbanos al mismo tiempo que el horizonte de la imaginación urbana "nunca estuvo tan clausurado en su capacidad proyectiva" (Gorelik, 2002: 125)

El panorama intelectual de la segunda década del milenio, en el ámbito de los estudios culturales urbanos, ha cambiado bastante respecto del momento en que Gorelik realizaba esta mordaz crítica. El uso de la noción de imaginarios ha culminado su apogeo y circula una pluralidad de temáticas y perspectivas que contrastan con la situación de quince años atrás. Sin embargo, hay un elemento que permanece constante en el uso de la noción de imaginarios. Se trata de una cierta laxitud en su empleo y aplicación. Si a comienzos del milenio el citado autor planteaba que en los estudios culturales urbanos solía observarse un tratamiento analítico que convertía a la ciudad en una "mera excusa para un torrente de metáforas en abismo, que no informan sino sobre sí mismas" (Gorelik, 2002: 125), en la actualidad ese rasgo sigue presente, a pesar de los esfuerzos de sistematización para hacerle frente (Ver al respecto, a modo de ejemplo, el número especial de Revista EURE del año 2007, coordinado por Alicia Lindón (EURE 33 (99)).

En este artículo propondremos un nuevo esfuerzo de sistematización en esa línea. Comenzaremos entregando una síntesis conceptual de la discusión sobre los imaginarios sociales. Nuestro propósito aquí es identificar una distinción estratégica en este campo de estudios, como es la que separa entre vertientes que ligan el imaginario a una condición de posibilidad de lo social, y las vertientes que destacan a los imaginarios como marcos de sentido para la acción humana en ciertos ámbitos de la realidad. Esta distinción nos permitirá entender que los imaginarios urbanos se sitúan en el segundo nivel de la distinción recién mencionada. Situados en ese segundo nivel, propondremos que los imaginarios urbanos tienen equivalentes conceptuales en otras tradiciones de pensamiento. Haciendo referencia a una de ellas, describiremos en detalle el modo en que los imaginarios urbanos son producidos $y$, en consecuencia, los momentos y aspectos a los que debe prestar atención un análisis pormenorizado de los mismos. Es lo que hemos llamado "mecánica" de producción de los imaginarios. A continuación indicamos que dicha propuesta tiene la pretensión de ser aplicable a otras realidades urbanas. Para hacer plausible esta aspiración, ejemplificamos nuestra propuesta a través de dos casos de investigación desarrollados con anterioridad. Concluimos el artículo con algunas reflexiones sobre la propuesta analítica. 


\section{La discusión sobre imaginarios sociales}

La discusión sobre el imaginario usualmente se inicia indicando su vínculo con nociones tales como símbolo, significado o imagen (Sartre, 2005). Ese "aire de familia" implica que muchas veces el imaginario se oponga a "lo real" o a "lo material", restringiendo su pertinencia al ámbito de la imaginación, o a una suerte de idealismo ingenuo. Este es sin duda un primer inconveniente. En este artículo tomamos partido por la idea de que lo imaginario no hace parte de un compartimento distinto de lo real, sino que es algo tan real como cualquier otra producción humana.

La relevancia de los imaginarios en actividad humana y en la vida social encuentra en C. Castoriadis una afirmación monumental (Castoriadis, 1998, 2007). Para este autor lo imaginario es la condición de emergencia de lo social, por cuanto la articulación con otros, es decir, la existencia de un colectivo humano, no se puede basar sino en este "magma" imaginario. Lo imaginario es sustrato y componente de la actividad humana.

Para este autor lo imaginario está en el origen de lo social, como también lo está en el origen de lo individual, puesto que tanto psique como sociedad, son entidades de carácter constituidoconstituyente y ambas corresponden a expresiones de lo imaginario en tanto flujo autoconstituido y (auto) constituyente.

Una perspectiva similar es la adoptada por G. Durand. De acuerdo a este autor, lo imaginario constituye una suerte de "sustrato" en el que se basa toda producción humana y social. De hecho, se trata de un sustrato al que toda la producción cultural de occidente busca modelar, canalizar, en incluso, recluir, de modo que sea posible el flujo de la racionalidad, generalmente en su versión estratégica (Durand, 2000, 2004).

Lo propio de lo imaginario es su ser constitutivamente "dilemático" o "anfibólico", es decir "ambiguo", porque comparte con su opuesto una cualidad común. Aquí emergen también sus rasgos de "complementariedad" y "contradictorialidad". De hecho, lo propio de los imaginarios, para este autor, se manifiesta en la operatoria de un tejido relacional de atributos y no en una enumeración de cualidades. Podemos ver, en consecuencia, que para G. Durand lo imaginario tiene también este carácter magmático de condición de posibilidad para la emergencia de lo social.

En otra línea, para el antropólogo francés M. Augé, los seres humanos nos vemos enfrentados desde el origen a la necesidad de simbolizar el mundo, el espacio y el tiempo, es decir, a la necesidad de volver la realidad concebible y viable. No podemos vivir en el espacio y el tiempo sin imaginarlos. Se trata de un impulso casi automático $y$, en ese sentido, anterior a la actividad social (Augé, 1997).

No obstante, en otro nivel, este mismo autor propone la idea del "triángulo de lo imaginario", para hacer referencia a los niveles donde se produce lo imaginario y a las formas en las que este imaginario circula y se asienta. Los vértices de este triángulo -que son al mismo tiempo fuentes desde las que surge- son el imaginario individual, el imaginario colectivo y la ficción.

La distinción en dos niveles que acabamos de ver en la conceptualización de lo imaginario de los tres autores mencionados, resulta central. En efecto, en un primer nivel se sitúa el imaginario social, en singular, entendido como condición de posibilidad para que surja lo social. En un segundo nivel encontramos los imaginarios sociales -generalmente tratados en plural-, entendidos como esquemas de organización y percepción del mundo que nos rodea.

El primer nivel de lo imaginario, es decir, el que refiere a la materia propicia para el surgimiento de lo social, es al que alude G. Durand cuando explica que los imaginarios sociales corresponden al "museo de todas las imágenes pasadas, posibles, producidas o por producir" $\mathrm{y}$ 
que se encuentran asociadas a términos tales como: pensamiento simbólico, razonamiento por similitud, metáfora, etc. (Durand, 2000). Mientras tanto, el segundo nivel refiere a lo que G. Durand vincula con los los arquetipos y los esquemas, en tanto orientan los desempeños prácticos de los individuos. Es a este mismo nivel que remite G. Balandier, en su concepción de los imaginarios como mecanismos operatorios que permiten producir orden, dando forma a aquello que no lo tiene (Balandier, 1993).

Algo similar encontramos en el trabajo de L. Pintos, para quien los imaginarios sociales son "visiones del mundo" y constructores del orden social (Pintos, 2000). Es decir, corresponden a las estructuras que hay tras las prácticas de los individuos o tras el operar de los sistemas. Para este autor, los imaginarios sociales serían precisamente las representaciones colectivas que organizan y gobiernan los sistemas de identificación y de integración social. En esta perspectiva, los imaginarios son esquemas construidos socialmente que nos permiten percibir, explicar e intervenir en la realidad.

La distinción entre estos dos niveles es, en consecuencia, crucial. Los imaginarios sociales como sustrato que hace posible la actividad humana, nos llevan a una reflexión ontológica sobre lo social, en tanto que los imaginarios sociales como esquemas o modos de observación que se utiliza de modo práctico para ver y comprender la realidad, remiten a una reflexión, con tintes fenomenológicos, respecto de los desempeños prácticos de los actores, tanto en el plano de la percepción como de la acción. La discusión sobre imaginarios urbanos se centra habitualmente en la segunda parte de la distinción, como veremos a continuación.

Efectivamente, un ejemplo relevante de recuperar en esta argumentación, debido a su magnitud y profundidad, es el del proyecto sobre Imaginarios Urbanos desarrollado en distintas ciudades de Latinoamérica y España, a comienzos del milenio, bajo la dirección de A. Silva y con el apoyo del Convenio Andrés Bello (Silva, 2003, 2004; Richard y Ossa, 2004). En ese proyecto, se entiende los imaginarios fundamentalmente como producciones mentales de los ciudadanos que marcan el modo de usar y evocar la ciudad. Junto con ello -y muy relacionado con lo que veremos más adelante en este artículo - el coordinador internacional del proyecto, A. Silva, plantea que la ciudad que es resultado de tales operaciones mentales tiene, a su vez, efectos concretos sobre la vida diaria de los habitantes.

En una vertiente similar se encuentra el trabajo de M. Lacarrieu. Para esta autora, los imaginarios urbanos corresponden a aquella dimensión de la vida social a través de la cual los habitantes dan sentido, significan y representan sus prácticas cotidianas y, en consecuencia, generan sus identidades. Para Lacarrieu, "los imaginarios sociales permiten estructurar y organizar el mundo social a partir de la construcción de modelos que operan simbólicamente a través de discursos y prácticas concretas" (Lacarrieu, 2007: 55).

Los ejemplos a mencionar podrían ser muchos. Lo importante de rescatar, sin embargo, es que distintos autores, desde distintas tradiciones de pensamiento, convergen en plantear que los imaginarios urbanos tienen como función primigenia, orientar los desempeños concretos de los habitantes de la urbe $y$, en consecuencia, que tiene incidencia sobre las formas que la ciudad adopta.

Cabe aquí explicitar nuestra postura en relación al carácter de entidad estructurante de la percepción que poseen los imaginarios urbanos: cuando hablamos de esquemas de percepción y organización, estamos aludiendo a una entidad de orden cognitivo que todos los seres humanos poseemos y ponemos en práctica. Una suerte de habilidad de procesamiento de la información, por establecer un símil con la informática. Sólo que dicha habilidad es modelada socialmente $y$, como toda habilidad, para existir debe ponerse en ejercicio. En consecuencia, cuando decimos que el imaginario es una entidad de orden cognitivo estamos refiriendo a una 
entidad que se basa en una competencia biológica. Cuando decimos que el imaginario está moldeado socialmente, estamos diciendo que dicha competencia biológica adquiere forma en el marco de las relaciones con otros, en el contexto de una sociedad y un tiempo determinados, y deviene un patrón o modelo de procesamiento que organiza la percepción. En este punto coincidimos con el filósofo N. Goodman, cuando plantea que percibir sin concebir es una operación "ciega" (Goodman, 1992: 14). Más aún, podemos afirmar que toda forma de percepción tiene siempre un componente imaginario.

Pero, ¿cómo es que la percepción adquiere ese carácter imaginario? $\mathrm{O}$, dicho de otra forma, ¿de qué manera se produce esos imaginarios que organizan y orientan nuestra percepción? Es aquí cuando conviene introducir un concepto distinto que puede facilitar comprender la noción de imaginarios sociales. Se trata del concepto de "trasfondo".

En este punto podríamos acudir a otras tradiciones filosóficas para clarificar la envergadura conceptual de una noción como la de imaginarios urbanos, como podría ser la perspectiva del "mundo de la vida" desarrollada en la fenomenología de Husserl y que tiene una aspiración comprensiva similar. De hecho, esta perspectiva conceptual ha tenido gran incidencia en la tradición sociológica que remonta al trabajo de A. Schütz (1995) y continúa con el de P. Berger y T. Luckmann (1995), teniendo su mayor desarrollo crítico en la propuesta habermasiana de un mundo de la vida opuesto a la racionalidad de los sistemas (Habermas, 2010). Hemos optado por la propuesta del "trasfondo" por tres razones. Primero, porque ofrece una claridad analítica que no encontramos en las propuestas del mundo de la vida. Segundo, porque resulta menos conocida en las ciencias sociales latinoamericanas, lo que hace que su introducción nos parezca relevante. Tercero, lo más importante, porque articula de modo explícito la relación existente entre la producción de representaciones específicas y la conformación de ese marco perceptivo e interpretativo que es nuestro foco de atención en este trabajo.

El concepto de trasfondo ha sido propuesto por el filósofo norteamericano J. Searle, quien le entiende como el conjunto de capacidades no intencionales, no conscientes y no representacionales que hacen posible que los seres humanos se desenvuelvan en el mundo (Searle, 1997; Campos, 2011). Para este autor, el trasfondo constituye un conjunto de condiciones para el funcionamiento de contenidos intencionales, por cuanto permite que se dé tanto la interpretación lingüística como la interpretación perceptiva. Además, el trasfondo facilita ciertas clases de predisposición haciendo a los individuos más proclives a ciertos tipos de conducta. Con "intencional" no aludimos aquí a "deliberado", sino que a la noción filosófica según la cual la actividad de la mente siempre refiere a un objeto.

En su discusión, Searle plantea que para entender cualquier tipo de enunciado (frase, texto, etc.) requerimos de un conocimiento que va más allá del conocimiento de las palabras que conforman nuestro idioma. Necesitamos un conocimiento de cómo se dan las cosas en la práctica. Ese conocimiento se encuentra almacenado en nuestra memoria y es utilizado cuando las circunstancias así lo requieren.

Proponemos, entonces, que la noción de trasfondo es un equivalente funcional de la de imaginarios sociales y que las distinciones analíticas que hace posible establecer, son también aquellas que permite la perspectiva de los imaginarios urbanos, tal como lo han puesto en evidencia los autores mencionados anteriormente.

Se desprende de lo hasta aquí dicho que el trasfondo no refiere a un contenido intencional específico, sino que a una entidad que permite comprender y dar sentido a los contenidos intencionales específicos con los que nos topamos en nuestra vida diaria. Dicho con un ejemplo, el trasfondo no es una frase, sino que nuestra capacidad de entender esa frase. 
No obstante, que seamos capaces de entender una frase, supone que hayamos almacenado en nuestra memoria una buena cantidad de ellas, así como reglas gramaticales y sintácticas. Esto quiere decir que, a pesar de no ser un contenido intencional específico, el trasfondo se nutre de contenidos intencionales específicos. Este aspecto resulta clave para comprender la mecánica de funcionamiento del trasfondo $y$, en consecuencia, para entender la operatoria de los imaginarios sociales. Retomando el ejemplo, el trasfondo no es una frase, sino que nuestra capacidad de entender dicha frase, capacidad que se ha desarrollado producto de haber escuchado y leído muchas frases, particularmente aquellas que se asemejan a la frase que tratamos de entender.

Resumiendo lo dicho hasta aquí, los imaginarios sociales son esquemas de percepción y organización que han sido generados a través de nuestra exposición a, y subsecuente "almacenamiento" de, contenidos intencionales y de otros contenidos de orden vivencial (sensoriales, por ejemplo), que quedan disponibles para nuestro desempeño práctico. Ahora bien, cuando decimos imaginarios "urbanos", nos referimos particularmente a aquellos esquemas que orientan nuestra percepción de, y nuestra acción en, la ciudad y el espacio urbano. En este sentido, entendemos que los imaginarios urbanos son una forma de imaginario social, cuyas reglas de funcionamiento son homólogas a las de otros imaginarios sociales, como podrían ser, por ejemplo, los imaginarios profesionales (Becker, 2009).

\section{La mecánica operatoria de los imaginarios urbanos}

Si los imaginarios urbanos son ese trasfondo que permite que percibamos y comprendamos la ciudad, y que ha sido construido mediante la producción permanente de contenidos intencionales, resulta plausible proponer que su conformación responde a una suerte de sedimentación de los mismos. Esto es, que los imaginarios urbanos corresponden al conjunto de representaciones y contenidos intencionales (Todo contenido intencional puede ser entendido como una representación de "ese algo" al que refiere.) que se ha producido sobre la ciudad y que son "almacenados" en la memoria por nosotros, habitantes de la urbe, quienes los utilizamos la mayor parte del tiempo de manera involuntaria, para dar sentido a nuestra experiencia citadina.

En esta perspectiva, todo contenido intencional y toda representación alimentan dicha capacidad. Sin embargo, aquellas representaciones específicas sobre la ciudad son particularmente relevantes en la producción de nuestros imaginarios urbanos. En consecuencia, la producción de representaciones de la ciudad es una de las principales vías de producción de imaginarios urbanos, por lo que nos detendremos en ella para entender la mecánica de producción de los mismos.

Cuando se produce una representación de la ciudad, por ejemplo, una fotografía de ella, difícilmente se da cuenta de todos los aspectos de la ciudad, o de todos los componentes de nuestra experiencia sobre la ciudad. En estricto rigor, hacer esto último es imposible: no podemos dar cuenta de toda nuestra experiencia de la ciudad y de toda la inmensidad de la misma a través de una representación. Normalmente, producir una representación de la ciudad implica remitirse a algún o algunos aspectos de ella que nos parezcan relevantes.

En este sentido, toda representación de la ciudad implica que su productor haga una selección entre una multiplicidad potencial de rasgos y decida referirse a uno o algunos en particular. Luego de ello, es necesario considerar que toda representación hace parte de un ámbito de actividad o esfera de utilización en la que cobra sentido (Fraenkel, 2007). por ejemplo, el ámbito del turismo, de la literatura, de la publicidad. El hecho de que haga parte de esta esfera de utilización supone que cobre una función y una utilidad $y$, en consecuencia, que el objeto representado, en este caso la ciudad, también cobre funciones y significados: funciones 
turísticas (por ejemplo, encanto), literarias (por ejemplo, evocaciones) o publicitarias (por ejemplo, atractivo). Pero la representación posee, además, la particularidad de que se da a conocer a otros, es decir, que se difunde entre un grupo y que sus contenidos específicos se dan a conocer a este grupo, de lo que se desprende que las funciones y significados propuestos para la ciudad quedan disponibles para que los usuarios de la representación los utilicen (Campos, 2011).

Tenemos entonces que esta secuencia de producción de representaciones puede ser dividida en cuatro momentos: primero, un productor percibe un aspecto de la realidad y decide referirse a él; segundo, ese productor genera una representación que inevitablemente posee una función y un significado; tercero, esa representación, con sus funciones y significados, es difundida; cuarto, tales funciones y significados quedan disponibles para los usuarios de dicha representación.

El último punto indicado, que funciones y significados queden disponibles para los usuarios de una representación, resulta fundamental, por cuanto permite destacar el hecho de que toda representación produce efectos sobre quienes la perciben, pero también permite distinguir entre dos tipos de representaciones: aquellas que se producen sin el propósito de incidir en la visión de otros (por ejemplo, una fotografía de la ciudad en un curso de fotografía) y aquellas que buscan incidir en otros (por ejemplo, la publicidad inmobiliaria). Vale decir, hay representaciones de la ciudad que están dirigidas a intervenir sobre nuestros imaginarios urbanos y, para hacerlo, deben actuar sobre nosotros, sus destinatarios.

Siguiendo el análisis planteado por Bourdieu para el caso de la literatura, cabe proponer que estas representaciones de la ciudad buscan actuar sobre sus usuarios, hablándoles a la sensibilidad (Bourdieu, 1992). Entonces, cada representación funciona como una muestra de algo relativamente específico sobre la ciudad y la vida urbana. Una muestra que se da a ver con todas las apariencias del sentido común, y que a través de una serie de procedimientos (narrativos, visuales, etc.), busca ser significativa para su destinatario y, así, "hacer trabajar los esquemas de su propia experiencia" (Lahire, 2001: 162), pero en una dirección específica: en el caso que nos convoca, el de la percepción e interpretación de la ciudad. Veamos ahora la operatoria de esta mecánica a través de dos ejemplos ilustrativos, surgidos investigaciones que hemos realizado anteriormente (Álvarez, 2015; Campos, 2011, 2011a, 2013).

Con los dos ejemplos que mencionaremos a continuación queremos demostrar dos aspectos principales. Primero, la mecánica u operatoria de la producción de imaginarios, de acuerdo a la cual siempre se trata de un proceso en el que un actor, o conjunto de actores, producen contenidos intencionales y representaciones cargadas de significados, que son entregadas a otros mediante un dispositivo particular de difusión, que actúa en el tiempo y en el espacio. Segundo, que los imaginarios urbanos se instalan como capacidades de decodificación de la ciudad, que funcionan aún sin la intención de quien las pone en práctica: es esa la principal cualidad de la "Ciudad Abreviada" y del "Barrio Alto", dos nociones que detallaremos a continuación.

\section{Ejemplo 1. El concurso "Santiago en 100 palabras": textos literarios en la producción de imaginarios urbanos}

Como breve pero necesaria introducción, podemos decir que "Santiago en 100 palabras" es un concurso literario organizado anualmente por Plagio -originalmente una revista literaria que devino organización cultural-, con el apoyo del Metro de la ciudad de Santiago y la empresa minera Escondida. Se ha realizado desde el año 2001 y su convocatoria ha sido, desde entonces, a escribir "cuentos breves" sobre la ciudad de Santiago o sobre la vida urbana contemporánea en general, que no superen las cien palabras. Desde entonces el concurso ha 
convocado a una gran cantidad de participantes: han participado alrededor de 400.000 microrelatos originales hasta el año 2012, según cifras de los organizadores. Se calcula que cada año participan, en promedio, 50 mil micro-relatos (http://www.santiagoen100palabras.cl/). quienes concursan por obtener alguno de los premios ofrecidos por los organizadores: tres premios en dinero para los tres primeros lugares y la publicación, como "menciones honrosas", de otros ocho relatos. A ello se ha sumado, en los últimos años, otros premios de reconocimiento social, como por ejemplo, un premio del público que vota en línea y elige su micro-relato favorito Esto ha cambiado a lo largo del tiempo, pero esta descripción es suficiente para los fines de este texto -. El conjunto de los micro-relatos premiados es publicado cada año en las estaciones y trenes del metro de Santiago, en afiches emplazados en los espacios destinados para la publicidad. Además, los organizadores del concurso editan anualmente un pequeño libro denominado "Los 100 mejores", con los que, a su juicio, constituyen los cien mejores relatos de los años precedentes. Entre los estudios relativos a Santiago en 100 palabras, cabe mencionar los trabajos de Mujica (2005) y Greene (2006).

La escritura de los micro-relatos de "Santiago en 100 palabras" supone que los autores reflexionen para definir respecto de qué van a escribir y cómo lo van a hacer. Detrás de cada micro-relato del concurso "Santiago en 100 palabras" hay, por lo tanto, marcos de referencia puestos en juego por los autores y puestos a disposición de los lectores para percibir y concebir la ciudad. Detrás de cada uno se encuentra una forma de ver y de dar a ver introduciendo la diferencia, la división, la separación. Esto es lo que P. Bourdieu llamaba el "efecto teoría (Bourdieu, 1992; Goodman, 1992).

La puesta en juego de tales marcos de referencia puede ser vista con claridad en el caso del tratamiento que se da a los lugares a los micro-relatos. No se trata de decir que los textos se reduzcan a hacer referencias a lugares. De hecho, los micro-relatos refieren a muchos otros elementos y factores. Escogimos el tratamiento dado a los lugares porque nos parece que es el ejemplo más claro para efectos de esta argumentación.

En el análisis que hicimos de la forma en que se aludía a los lugares, pudimos detectar que hay dos formas principales de asignación de significado para los lugares y, en consecuencia, dos formas principales de producción de imaginarios urbanos a través de la escritura de los microrelatos (Campos, 2011). Primero, mediante el uso de referencias concisas a lugares, se busca denotar y connotar ciertos aspectos a través de su articulación con los distintos componentes del relato, tales como los personajes, la temática y las referencias temporales. Segundo, cuando el relato se centra en un lugar, a través del desarrollo de una perspectiva de caracterización del mismo, en la que se despliega modos de adjetivación y/o asociaciones de significado. La metodología de análisis empleada para llegar a estas aseveraciones ha sido detallada en publicaciones anteriores de uno de los autores (Campos 2011; Campos y Rojas, 2015). Cabe consignar aquí, sin embargo, que el corpus en base al cual realizamos estos planteamientos estuvo compuesto por 595 micro-relatos publicados por los organizadores del concurso en el formato de libros de bolsillo, entre los años 2001 y 2012 . Ese conjunto de textos fue analizado mediante un procedimiento cualitativo de análisis temático, seguido de lo cual se realizó un procedimiento cuantitativo de análisis de contenido que permitió la construcción y uso de una base de datos.

A continuación presentamos un micro-relato que resulta ejemplar de la primera forma, "De Mall", y un ejemplo de la segunda modalidad, el micro-relato "Río Mapocho".

\section{De mall}

"Ella se probó varios vestidos de noche mientras yo revisaba unas chaquetas de cuero. Tras eso, nos detuvimos sospechosamente más tiempo del habitual frente a las argollas de 
una joyería. Oscurecía ya, mientras paseábamos por el cine, evaluando cuál de las películas allí exhibidas compraríamos pirateada en Ahumada. Ya se acababa el día y aceleramos para alcanzar a tomar el último viaje del Metro. Llegamos a nuestra estación felices, de la mano, aun sabiendo que nos quedaban más de quince cuadras de camino. Por suerte nos alcanzó la plata para un par de sopaipillas."

Víctor Badaracco, 27 años, Puente Alto

\section{Río mapocho}

"Verano. Me visitó Oliver, el alemán. Un día, volvió quejándose sobre el raquítico río Mapocho. Yo sabía que era un río "importante", dijo burlándose. Era verdad. Me avergoncé todo el otoño del hilo turbio que corría miserablemente. No es que yo defendiera al Mapocho, pero ese invierno creció y se desbordó como nunca (recuperando la Alameda, quizás). En primavera, le envié fotografías del Mapocho arrastrando casas y automóviles. ¿Qué creía, que tenemos un río picante? El verano siguiente visité a Oliver para espiar sus ríos. Pero llegué a Alemania en pleno invierno. Me hice el leso respecto del tema, obviamente."

Carlos López, 33 años, Quilicura

Las dos modalidades de alusión a lugares que hemos consignado se pueden observar en los textos de manera individual y aislada. Sin embargo, cuando se piensa en el concurso en su conjunto, emerge una tercera forma, de acuerdo a la cual los lugares adquieren significado por la recurrencia con que son mencionados. Esto quiere decir que tenemos por un lado, que los textos pueden generar alguna forma de afectación en los lectores por su funcionamiento individual, esto es, porque los conmueven o persuaden debido a su particular dosificación de elementos, pero, junto con ello, tenemos que la reiteración de referencias espaciales, en un conjunto de micro-relatos, a lo largo del tiempo, también puede generar un efecto imaginario en los lectores.

En esa dirección, uno de los efectos de este funcionamiento recurrente es el de producir una representación de la ciudad de Santiago en que ésta se resume en un conjunto de lugares: los lugares que son más frecuentemente mencionados en los micro-relatos (Fig. 1). 


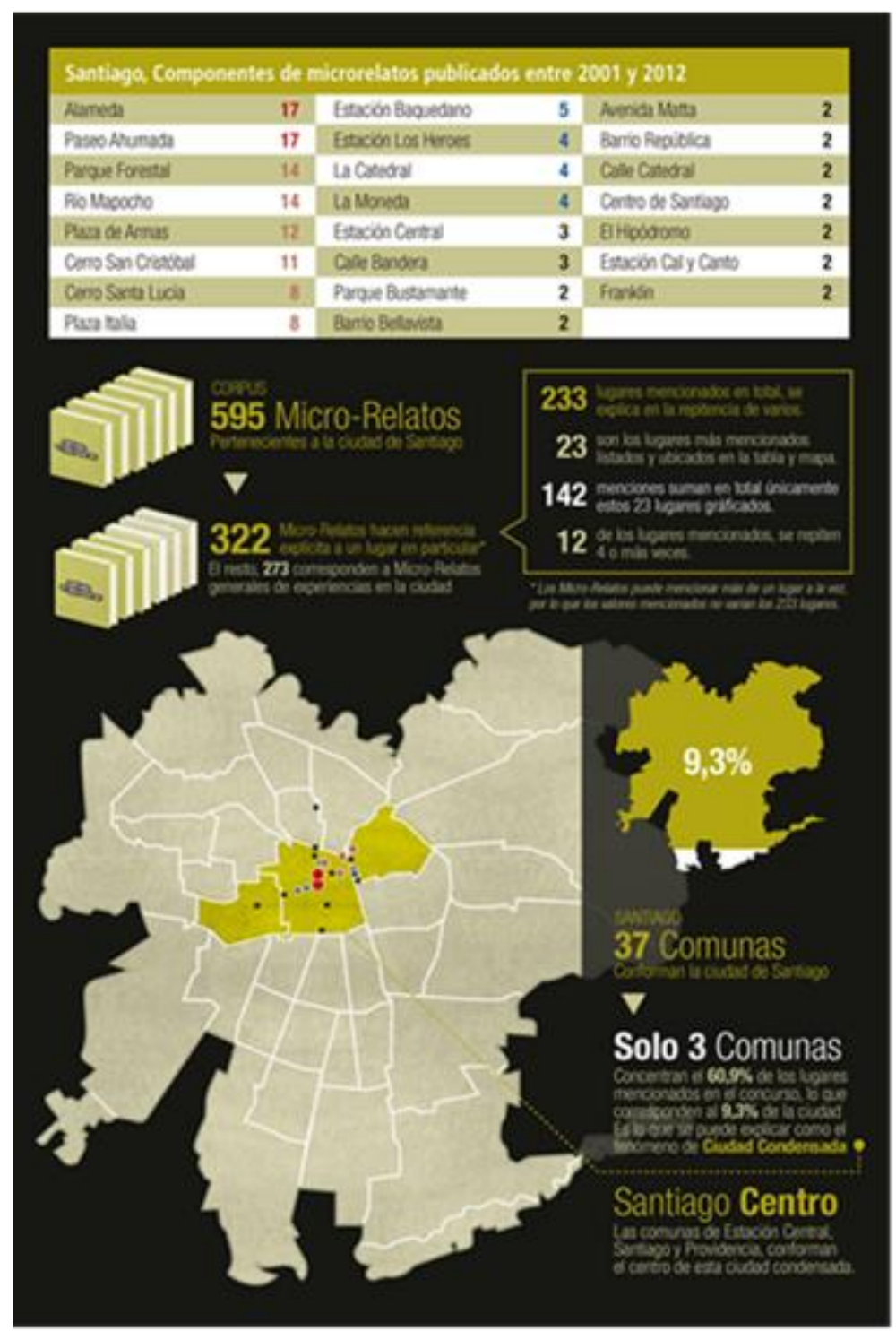

Fig. 1 Lugares mencionados en los micro-relatos publicados entre 2001 y 2012. Fuente: Elaboración propia.

La Fig. 1 es elocuente en mostrar que ocho lugares del listado concentran 101 menciones en el corpus de micro-relatos. Esta concentración es una información muy elocuente de los lugares que, en términos de K. Lynch, concentran la "imaginabilidad" de la ciudad de Santiago (Lynch, 2000: 19). Estos lugares parecen causar una fuerte imagen en cualquier observador de la ciudad y, por lo tanto, parece que concentran el acuerdo de los participantes en el concurso en cuanto a que son los lugares susceptibles de expresar sus visiones de la ciudad de Santiago. Es pertinente pensar, en consecuencia, que estos son los lugares que, a juicio de los habitantes de la ciudad, son capaces de transmitir el significado de la misma y que, en una hipotética situación futura, serán tales lugares los empleados por otros participantes para referir a la ciudad de Santiago.

Por otro lado, esta concentración es también de orden territorial. Si pusiéramos estos lugares en un mapa podríamos constatar que ellos se encuentran en un área extremadamente pequeña 
en comparación con el tamaño de la ciudad de Santiago. Resulta plausible, entonces, proponer que se trata de una representación de la ciudad relativamente inequívoca y potente en el proceso de modelamiento de referencias colectivas que balizan el espacio de la ciudad, ya que tenemos un conjunto de lugares que evocan la ciudad de Santiago por una especie de "asociación privilegiada" (Genette, 1991: 120), configurando una "Ciudad Abreviada".

La ciudad abreviada puede ser entendida al modo de una sinécdoque, en el entendido que, al igual que en el procedimiento retórico, aquí es toda la ciudad de Santiago que es designada por tan sólo una porción restringida de ella.

Nos encontramos, entonces, frente a una secuencia como la descrita en el apartado anterior, en la que un conjunto de productores de representaciones -en este caso participantes en el concurso- percibe la ciudad de un modo y, luego de ello, cada uno de modo independiente decide representarla haciendo referencia a un lugar, al que indefectiblemente le asigna un significado. Esa representación es publicada y difundida en distintos formatos entre los que se cuenta los libros de bolsillo, quedando disponible para los lectores de dichos libros. La reiteración de las referencias a los mismos lugares que genera el dispositivo de exposición del concurso puede generar, a su vez, una orientación de los modos habituales de percibir la ciudad de los lectores, justamente en razón de la repetición de dichas referencias espaciales y/o la intensidad de sentido asignada a alguna de esas representaciones literarias en particular (Campos, 2011).

\section{Ejemplo 2. La publicidad inmobiliaria en la construcción de imaginarios urbanos}

Consideramos que el caso de la publicidad sigue los mismos principios recién descritos. De hecho, en términos publicitarios se habla de recordación y se plantea que una publicidad más o menos efectiva se mide justamente por esta tasa de recordación o, dicho de otra forma, por la probabilidad que tiene de ser recordada.

Para ilustrar estas ideas hemos seleccionado la revista Vivienda y Decoración, del diario El Mercurio. Esta selección se basa en que esta revista es la más antigua y la que actualmente lidera el mercado de revistas cuyas temáticas se centran en el urbanismo y la arquitectura. Esto además de pertenecer al holding periodístico más grande de Chile. Su público objetivo son los sectores socioeconómicos alto y medio alto, cuyo poder adquisitivo los convierte en potenciales clientes de los proyectos inmobiliarios que se publicitan en este soporte.

Asimismo, hemos optado, por la publicidad inmobiliaria porque es influyente en cuanto a orientar a los lectores en el proceso de compra. Sobre todo, porque la publicidad en formato revista es altamente aceptada por sus receptores pues no genera rechazo, entrega prestigio a las marcas, es atractiva para los lectores y además es un medio que es considerado por los expertos en marketing como de gran ubicuidad.

A partir de un análisis a la publicidad inmobiliaria, proponemos que cada pieza publicitaria produce significados e imaginarios por medio de numerosas técnicas persuasivas, las que pueden variar desde una ilustración a un texto o a una fotografía (Ferrer, 1997). Además, en el caso de la publicidad inmobiliaria, tales imágenes pueden ser intervenidas, por ejemplo, intensificando el azul del cielo, eliminando cables de electricidad que ensucien el cuadro, aumentando los niveles de verdes que existen en la imagen, embelleciendo a los personajes que se exponen en la fotografía 0 , incluso, eliminando entornos para fortalecer el protagonismo de la vivienda. De hecho, el color es un recurso que se utiliza con el objetivo de ir afectando la representación de un proyecto inmobiliario en particular y fortalecer sus connotaciones. En este contexto, serán el verde o el azul, en su multiplicidad de gamas, los colores más ocupados 
debido a la carga representacional que poseen, al ser fácilmente asociados a la naturaleza y a lo diáfano.

En cuanto a la composición gráfica, las tipografías cargan significantes que la publicidad inmobiliaria también utiliza para fortalecer los mensajes y sus connotaciones. De este modo, una tipografía clásica puede hacer eco de un pasado cargado de tradicionalismo o bien, al ser menos ornamentada en sus trazos, hacer referencia a la modernidad. Sobre este punto, en la última década la elegancia ha sido destacada en la mayoría de las publicidades referidas a la vivienda, por lo que la tipografía ocupada responde a categorías de trazos caligráficos que se relacionan con el arte, con lo poco recargado y con la suavidad en la curva.

Por otro lado, la construcción del imaginario que se encuentra implícita en la publicidad, por medio de los recursos gráficos empleados, se ve fortalecida por el mensaje o por el texto escrito que se busca instaurar. De este modo, podemos dar cuenta de una serie de conceptos que la publicidad inmobiliaria ocupa para potenciar los beneficios de habitar en determinada vivienda, entre ellos la ubicación, la cercanía a servicios, la naturaleza, el lujo, la conectividad o la seguridad. Asimismo, la denominación de los proyectos también hará eco de lo anterior utilizando la ubicación y la naturaleza como aspectos clave de su composición.

Con la finalidad de dar más solidez a nuestra argumentación hemos seleccionado el mismo aspecto que para Santiago en 100 palabras, esto es, nos hemos concentrado en el tratamiento dado por la publicidad inmobiliaria de la revista a los lugares de la ciudad de Santiago.

Cuando orientamos nuestro análisis en esa dirección constatamos que uno de los efectos sobre los imaginarios urbanos generado por la revista la construcción simbólica del "Barrio Alto" (Álvarez, 2015). En efecto, resulta plausible proponer que su publicidad inmobiliaria ha destacado de manera sistemática un conjunto de comunas del sector oriente de Santiago, vinculándolas a la adquisición de un determinado estatus. Esto, considerando que el público objetivo de la revista y por consecuencia de los avisos es el sector socioeconómico ABC1 y C2 (Ariztía y Simone, 2012). De este modo, comunas como Las Condes, Vitacura, Providencia, La Reina $y$, en el último decenio, sectores como La Dehesa o Chicureo, han sido foco del avisaje publicitario de la revista, destacando su ubicación privilegiada.

El uso del mapa ha sido un recurso gráfico dirigido a fortalecer estas ideas. Se refuerza así la idea de que estas comunas componen un sector para personas que buscan escapar de todo lo que conlleva el centro de la ciudad, que es presentado por esta publicidad como caótico, peligroso y carente de tranquilidad. Ese desplazamiento en la ciudad, esa invitación a ser parte de este exclusivo sector, supone un alto poder adquisitivo por parte de sus habitantes, quienes deben tener los recursos suficientes para disfrutar de todo su potencial, por cuanto el "Barrio Alto" está vinculado al paisaje y a la vista a la cordillera, pero también a la conectividad y a la accesibilidad de centros comerciales y colegios. La publicidad inmobiliaria fortalecerá, entonces, la idea de lo "lejos pero cerca", de la huida a lo nuevo, a lo distinto y lo selecto, a lo distintivo, a lo que nunca envejece en una atemporalidad propia de la utopía.

De esta forma, el "Barrio Alto" que construye la publicidad deja de referir a un sitio preciso y se convierte en una suerte de atractor, en una etiqueta que da valor y a la que conviene acercarse. Su geografía inicial se relativiza y aparecen, así, nuevos sectores que también son o aspiran a ser- "Barrio Alto", como Peñalolén, La Florida y Huechuraba.

Podemos ejemplificar lo descrito en el siguiente aviso publicitario, cuyo eslogan es: "Para los que creen posible escapar de la ciudad sin salir de ella". Aquí el logo pareciera emular un pequeño trazo caligráfico a mano alzada, casi una pincelada gruesa. El nombre del conjunto "Quinchamalí de los Andes" rescata precisamente el valor que le otorga la publicidad a la Cordillera de los Andes. La imagen, en tanto, es una suerte de valle inmerso en una gran 
ciudad que se observa a lo lejos como una aglomeración de luces propia de las urbes. En su parte inferior se encuentra un mapa en el que se hace referencia sólo a las principales avenidas, reforzando precisamente valores tales como la cercanía y la conectividad. Finalmente, en su costado hay un render, o imagen proyectada en 3D, en el que se observa un edificio rodeado de vegetación, actuando como reforzador de la idea de "ciudad jardín" que anteriormente mencionábamos.

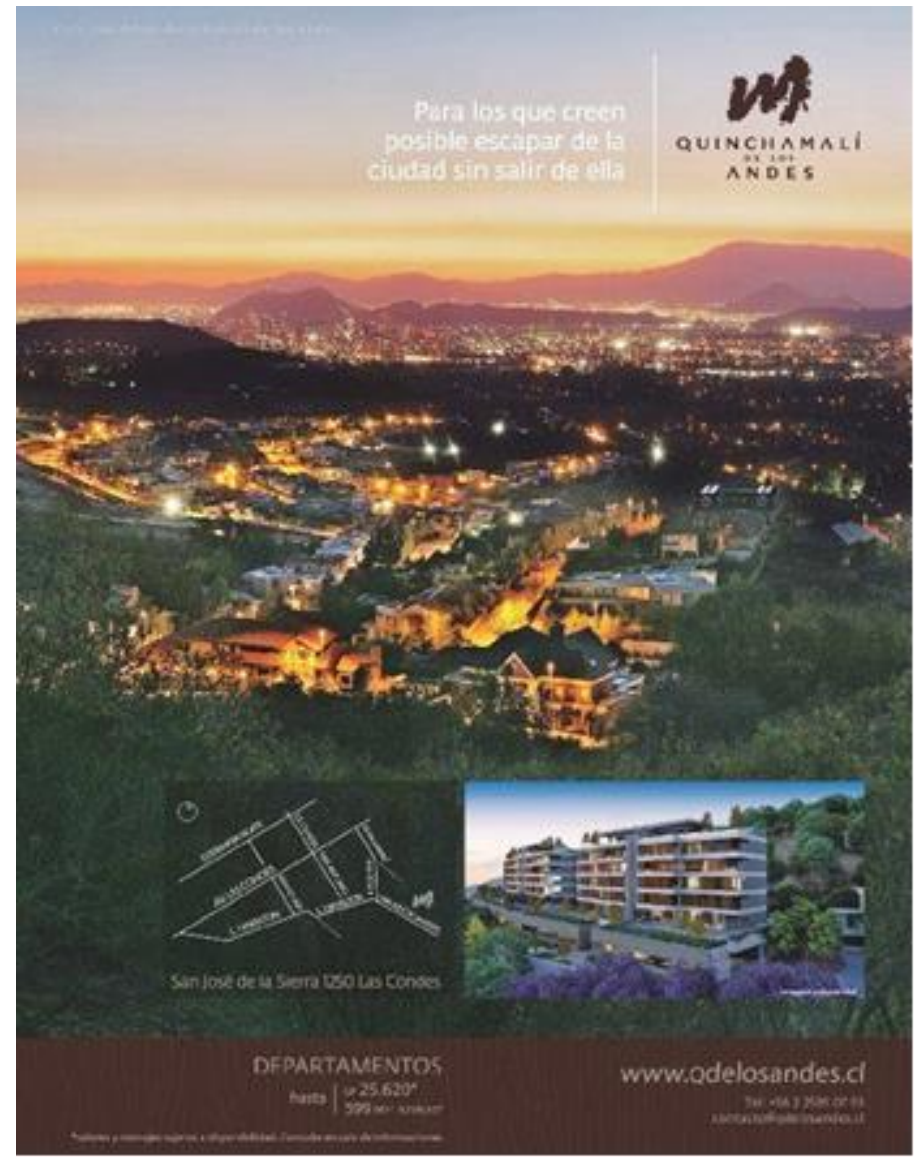

Fig. 2 Publicidad inmobiliaria y la utopía de escapar de la ciudad. Fuente: Revista VD, 2014.

Nuevamente estamos aquí frente a una representación de la ciudad relativamente inequívoca y potente en el proceso de modelamiento de referencias colectivas. La ciudad queda organizada territorial y semánticamente, primero, instalando a un sector como el depositario de la exclusividad y la distinción y, segundo, reforzando la distinción preposicional entre bajo y alto que, más allá de aludir a una situación geográfica de una ciudad instalada a los pies de la cordillera, organiza las interacciones sociales y las significaciones de sus habitantes.

La secuencia observada es equivalente a la planteada de modo teórico en el apartado sobre la mecánica de producción de los imaginarios y a la ilustrada a través del ejemplo de "Santiago en 100 palabras", esto es, un productor o, en este caso, un conjunto de productores generan una representación de una parte de la ciudad de Santiago, intentando relevar algunos de sus aspectos y generar un significado asociado a la distinción. Para ello ocupan una multiplicidad de recursos (lo que en el caso de los micro-relatos tiene que ver fundamentalmente con la escritura). Esa representación es difundida entre los lectores de la revista y, como producto de su sistematicidad y reiteración en el tiempo, esa representación queda disponible para ellos y, 
más concretamente, orienta los modos en que perciben y organizan espacial y simbólicamente la ciudad de Santiago.

\section{Conclusión}

En nuestra discusión planteábamos que los imaginarios urbanos son esquemas de percepción y organización de la ciudad que surgen de nuestro almacenamiento de representaciones y contenidos intencionales, y que quedan disponibles para nuestro desempeño práctico posterior. Con la descripción de ambos ejemplos hemos mostrado cómo las nociones de "ciudad abreviada" y de "barrio alto" constituyen, justamente, categorías que hacen que percibamos y organicemos la ciudad de modos particulares. Vale decir, se trata de categorías que han comenzado a funcionar de modo práctico y a tener efectos del mismo orden, por cuanto orientan las formas en que percibimos y concebimos la ciudad de Santiago. De manera concisa hemos planteado en nuestra argumentación que la ciudad deviene imaginable a través de un conjunto de lugares y es organizada socialmente en función de una distinción preposicional.

Por cierto, al nombrarlas de ese modo - "ciudad abreviada" y "barrio alto" -, es decir, al convertirlas en categorías, ya estamos haciendo de ellas dos representaciones específicas, que pueden materializarse en un mapa o en un afiche. Sin embargo, lo que hemos querido resaltar es que estas dos categorías son, en realidad, dos formas en las que se expresa una mecánica que opera de modo práctico, esto es, que se encuentra en proceso, actuando entre los destinatarios y usuarios, los lectores de los micro-relatos del concurso y los lectores de las publicidades de la revista.

Lo anterior equivale a decir que ambas categorías se constituyen en imaginarios urbanos, es decir, en disposiciones que dan forma a nuestras experiencias y que permiten comprender y dar sentido a otras representaciones - publicitarias y literarias, entre otras- con las que nos encontramos de forma habitual en nuestra vida diaria.

Consideramos que la mecánica de producción de imaginarios urbanos ilustrada a través de ambos ejemplos nos muestra la relevancia que tienen la sistematicidad y la reiteración de representaciones y contenidos intencionales, que muchas veces pasan inadvertidos debido a su extensión temporal. El análisis sistemático que está a la base del trabajo con ambos ejemplos interviene justamente sobre esa extensión temporal, ya que nos muestra, de modo sincrónico, el efecto que genera un proceso que es gestado durante años. En este sentido, cabe plantear que el mismo tipo de análisis resulta plausible para cualquier producción representacional generada a lo largo del tiempo, como podría ser la política pública, una escuela arquitectónica o la producción cinematográfica, por dar sólo algunos ejemplos.

No obstante, es con base en esa mecánica, aplicable a distinto tipo de producciones representacionales, que un análisis específico puede llevarnos a la detección de fenómenos singulares. En ese sentido, como mencionamos anteriormente, un aspecto en el que los dos ejemplos trabajados difieren es el de la intención que hay puesta tras la producción del "barrio alto" y de la "ciudad abreviada": en el primer caso se trata de una producción intencional, mientras que en el segundo es casi un efecto colateral. Esa diferencia en las intenciones está conectada, por cierto, a los intereses y propósitos de actores específicos que han producido estas categorías y que, en el caso de la Revista Vivienda y Decoración, son fundamentalmente intereses comerciales.

De ello se desprende que la producción de un imaginario está, en este caso, ligada a generar un esquema de valoración económico de la ciudad; un imaginario de acuerdo al cual la ciudad es una entidad que posee divisiones y jerarquías simbólicas y en el que prime la lógica de la distinción (Bourdieu, 1998). Es en función de esa lógica distintiva, específica a este imaginario, 
que la categoría "barrio alto" adopta una importante plasticidad desplazándose a diferentes lugares de la ciudad con el propósito de incrementar el beneficio comercial de los actores que están tras la producción de dicho imaginario.

Junto con lo anterior, la propuesta efectuada busca mostrar que hay efectos representacionales que se producen con independencia de la voluntad o intención de los autores. En este sentido, los dos ejemplos utilizados señalan un contraste: en un caso no hay intención en abreviar la ciudad; en el otro sí hay intención de destacar el barrio alto. Sin embargo, en ambos casos se producen efectos en el plano de orientar nuestras formas de percepción, apreciación y valoración de la ciudad de Santiago.

La exposición realizada nos muestra cómo, tanto la "Ciudad Abreviada" como el "Barrio Alto", partiendo como representaciones específicas de un determinado aspecto de la ciudad, se configuran, de modo progresivo, como habilidades de de-codificación que poseen los individuos, y que comienzan a operar de modo no intencional, asignando sentido a la ciudad en que vivimos. Es ahí donde se encuentra su mayor potencial para dar forma a nuestra experiencia urbana.

\section{Referencias}

ÁLVAREZ Bové, Romina, Construcción de imaginarios urbanos del habitar. Caso de la revista Vivienda y Decoración, Santiago de Chile, Tesis para optar al grado de Magíster en Hábitat Residencial, Universidad de Chile, 2015, 300 págs.

ARIZTÍA, Tomás; De Simone, Liliana, V\&D: Construyendo el gusto urbano, Entrevista, Revista Bifurcaciones, 2012. En línea: http://www.bifurcaciones.cl/2012/11/paula-veliz-construyendo-el-gustourbano/

AUGÉ, Marc, La guerra de los sueños, Barcelona, España, Editorial Gedisa, Serie Cla-de-ma, 1997, 158 págs., ISBN 8474326605.

BALANDIER, Georges, El desorden. La teoría del caos y las ciencias sociales, $3^{\circ}$ edición, Barcelona, España, Editorial Gedisa, 1993, 240 págs., ISBN 9788474323528.

BECKER, H. Los trucos del oficio, Editorial Siglo XXI, Buenos Aires, Argentina, 2009, 296 págs., ISBN 9789876290883.

BERGER, Peter; Luckmann, Thomas, La construcción social de la realidad, Buenos Aires, Argentina, Editorial Amorrortu, 1995, 233 págs., ISBN9789505180097.

BIFURCACIONES, "Santiago en más de 100 palabras, entrevista a Carmen García y Sylvia Dümmer de Revista Plagio" en Revista Bifurcaciones n¹, diciembre-febrero 2004, ISSN 0718-1132. En línea: http://www.bifurcaciones.cl/2004/12/santiago-en-mas-de-100-palabras/

BOURDIEU, Pierre, Les règles de l'art. Paris, Francia, Editions du Seuil, 1992, 480 págs., ISBN 9782020181594.

BOURDIEU Pierre, La Distinción. Criterio y bases sociales del gusto, Barcelona, España, Editorial Taurus, 1998, 600 págs., ISBN 9788430603381.

CAMPOS Medina, Luis, Les enjeux de la représentation de la ville: Santiago du Chili en cent mots, Saarbrücken, Alemania, Editions universitaires européennes, 2011, 404 págs., ISBN 6131591083.

CAMPOS Medina, Luis, "Representaciones de la ciudad en cien palabras: narraciones breves y significaciones durables" en Revista Kütral Volumen II n 97, pp. 117, Julio 2011, ISSN 07189842.

CAMPOS Medina, Luis, "Las violencias de la urbe. Un repertorio inacabado" en DE VIVANCO, Lucero (ed.) Memorias en tinta. Ensayos sobre la representación de la violencia política en Argentina, Chile y Perú, Santiago de Chile, Ediciones Universidad Alberto Hurtado, 2013, ISBN 9789569320446. 
CASTORIADIS, Cornelius, La Institución Imaginaria de la Sociedad. El imaginario social y la institución, Volumen 2, Buenos Aires, Argentina, Tusquets Editores, 2007, 576 págs., ISBN 9871210566.

CASTORIADIS, Cornelius, "Lo imaginario: la creación en el dominio históricosocial" en CASTORIADIS Cornelius, Los dominios del hombre. Las encrucijadas del laberinto, Barcelona, España, Editorial Gedisa, 1998, ISBN 9788474322996.

DURAND, Gilbert, Lo imaginario, Barcelona, España, Ediciones del Bronce, 2000, 165 págs., ISBN 9788484530152.

DURAND, Gilbert, Las estructuras antropológicas del imaginario: introducción a la arquetipología general, México, Fondo de la Cultura Económica, 2004, ISBN 9789681672065.

FERRER Rodríguez, Eulalio, El lenguaje de la publicidad, México, Editorial Fondo de cultura económica de España, 1997, 260 págs., ISBN 9789681650681.

FRAENKEL, Béatrice, "Actes d'écriture: quand écrire c'est faire" en Langage et Société n¹21-122, pp. 101-112, septiembre-diciembre, 2007, ISSN 01814095.

GENETTE, Gérard, Fiction et diction, Paris, Francia, Seuil, 1991, 150 págs., ISBN 9782020128513.

GOODMAN, Nelson; Popelard, Marie-Dominique, Manières de faire des mondes, Editions Jacqueline Chambon, 1992, 193 págs., ISBN 9782877110730.

GORELIK, Adrian, "Imaginarios urbanos e imaginación urbana. Para un recorrido por los lugares comunes de los estudios culturales urbanos" en Revista EURE Volumen XXVIII n83, pp. 125-136, mayo 2002, ISSN 0250-7161.

GREENE, Ricardo, Mi Santiasco Querido: Exploraciones del imaginario urbano en cien palabras, Tesis presentada al Instituto de Estudios Urbanos y Territoriales para optar al Grado académico de Magister en Desarrollo Urbano, Pontifica Universidad Católica de Chile. 2006. En línea:

http://www.bifurcaciones.cl/MiSantiascoQuerido.pdf

HABERMAS, Jürgen, Teoría de la acción comunicativa, $1^{\circ}$ edición, Madrid, España, Editorial Trotta, 2010, 992 págs., ISBN 9788498790726.

HIERNAUX, Daniel, "Los imaginarios urbanos: de la teoría y los aterrizajes en los estudios urbanos" en Revista EURE Volumen XXXIII n99, pp. 17-30, agosto 2007, ISSN 0250-7161.

LAHIRE, Bernard, L'homme pluriel, Les ressorts de l'action, Paris, Hachette Littératures. Paris, Francia, Editorial Nathan, 2001, 271 págs., ISBN 2091908983.

LINDÓN, Alicia, "Los imaginarios urbanos y el constructivismo geográfico: los hologramas espaciales" en Revista EURE Volumen XXXIII n99, pp. 31-46, agosto 2008, ISSN 0250-7161.

LYNCH, Kevin, L'image de la cité, Paris, Francia, Editorial Dunod, 1999, 221 págs., ISBN 9782100037162

MUJICA, M., "Santiago en 100 palabras: escenas y fragmentos de la memoria" en Revista Eure Volumen XXXII n92, pp. 123-130, 2005, ISSN 0250-7161.

MUSSET, Alain, "Entre la ciencia ficción y las ciencias sociales: el "lado oscuro" de las ciudades americanas" en Revista EURE Volumen XXXIII n99, pp. 65-78, agosto 2007, ISSN 0250-7161.

OSSA, Carlos; Richard, Nelly, Santiago imaginado, Bogotá, Colombia, Universidad Nacional de Colombia, 2004.

PINTOS, Juan Luis, "Construyendo Realidad(es): Los Imaginarios Sociales. Santiago de Compostela" en Revista del Cono Sur de Psicología Social y Política n¹, pp. 7-24, 2000, ISSN 1666-7085.

SARTRE, Jean Paul, L'imaginaire: psychologie, phénoménologique de l'imagination, París, -francia, Gallimard, 2005. 
SEARLE, John, La construcción de la realidad social, Barcelona, España, Editorial Paidós, Serie Paidós Básica, 1997, 236 págs., ISBN 9788449304217.

SCHUTZ, Alfred, El problema de la realidad social, $3^{\circ}$ edición, Buenos Aires, Argentina, Editorial Amorrortu, 1995, 336 págs., ISBN 9789505182510.

SILVA, Armando, Metodología de investigación en imaginarios urbanos: hacia el desarrollo de un urbanismo desde los ciudadanos, Bogotá, Colombia, Editorial CAB, 2004.

SILVA, Armando, Bogota imaginada, Bogotá, Colombia, Taurus, 2003, 334 págs., ISBN 9789587041132. 